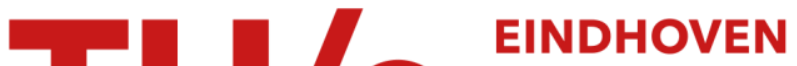 UNIVERSITY OF TECHNOLOGY
}

\section{The mechanism of oxygen reduction at iron tetrasulfonato- phthalocyanine incorporated in polypyrrole}

\section{Citation for published version (APA):}

Elzing, A., Putten, van der, A. M. T. P., Visscher, W., \& Barendrecht, E. (1987). The mechanism of oxygen reduction at iron tetrasulfonato-phthalocyanine incorporated in polypyrrole. Journal of Electroanalytical Chemistry and Interfacial Electrochemistry, 233(1-2), 113-123. https://doi.org/10.1016/0022-0728(87)85010-6

DOI:

10.1016/0022-0728(87)85010-6

Document status and date:

Published: 01/01/1987

\section{Document Version:}

Publisher's PDF, also known as Version of Record (includes final page, issue and volume numbers)

\section{Please check the document version of this publication:}

- A submitted manuscript is the version of the article upon submission and before peer-review. There can be important differences between the submitted version and the official published version of record. People interested in the research are advised to contact the author for the final version of the publication, or visit the $\mathrm{DOI}$ to the publisher's website.

- The final author version and the galley proof are versions of the publication after peer review.

- The final published version features the final layout of the paper including the volume, issue and page numbers.

Link to publication

\section{General rights}

Copyright and moral rights for the publications made accessible in the public portal are retained by the authors and/or other copyright owners and it is a condition of accessing publications that users recognise and abide by the legal requirements associated with these rights.

- Users may download and print one copy of any publication from the public portal for the purpose of private study or research.

- You may not further distribute the material or use it for any profit-making activity or commercial gain

- You may freely distribute the URL identifying the publication in the public portal.

If the publication is distributed under the terms of Article 25fa of the Dutch Copyright Act, indicated by the "Taverne" license above, please follow below link for the End User Agreement:

www.tue.nl/taverne

Take down policy

If you believe that this document breaches copyright please contact us at:

openaccess@tue.nl

providing details and we will investigate your claim. 


\title{
THE MECHANISM OF OXYGEN REDUCTION AT IRON TETRASULFONATO-PHTHALOCYANINE INCORPORATED IN POLYPYRROLE
}

\author{
A. ELZING, A. VAN DER PUTTEN, W. VISSCHER and E. BARENDRECHT \\ Laboratory for Electrochemistry, Department of Chemical Technology, Eindhoven Unwersity of Technology. \\ P.O. Box 513, $5600 \mathrm{MB}$ Eindhoven (The Netherlands)
}

(Received 19th December 1986; in revised form 7th April 1987)

\section{ABSTRACT}

The reduction of oxygen at iron tetrasulfonato-phthalocyanine (FeTSPc) incorporated in polypyrrole is studied. Compared with the results of FeTSPc adsorbed on pyrolytic graphite (Cp), a remarkable shift in the reduction onset potential in $0.05 \mathrm{M} \mathrm{H}_{2} \mathrm{SO}_{4}$ is observed, but unfortunately thin polypyrrole/ $\mathrm{FeTSPc}$ films show high instability. Thicker films (equivalent to $10 \mathrm{mC}$ or more) are more stable and lead to an increased four-electron reduction of oxygen. It is proposed that dimeric FeTSPc species are present in polypyrrole and that they are responsible for the marked shift in the reduction onset potential.

\section{INTRODUCTION}

Oxygen reduction at FeTSPc adsorbed on pyrolytic graphite $(\mathrm{Cp})$ in basic media is characterized by an $i-E$ curve consisting of two waves, as was observed by Zagal et al. [1]. For FePc (iron phthalocyanine) adsorbed on graphite, we observed similar behaviour [2]. Recently, we proposed a mechanism [3] in which the wave at low overpotential (prewave) is ascribed to dimer species, while the second wave (main wave) is attributed to monomer species. Oxygen reduction has also been investigated at FeTSPc incorporated in polypyrrole, a conducting polymer, by Bull et al. [4]. For CoTSPc incorporated in polypyrrole, measurements have been published by Florit et al. [5] and also by us [6].

The question arises as to whether we are dealing here with dimers or monomers of FeTSPc. To answer this question, we also investigated oxygen reduction at FeTSPc incorporated in polypyrrole.

For the $\mathrm{pH}$ dependence of the oxygen reduction at FeTSPc adsorbed on $\mathrm{Cp}$, Zagal-Moya [7] found that the prewave potential shows a more or less $p H$-dependent Nernstian behaviour for the $\mathrm{pH}$ range $3-12$; this means that no shift in potential is 
observed, if as the reference electrode a $\mathrm{pH}$-dependent electrode such as the reversible (Pt-)hydrogen electrode (RHE) is used. For the main wave, the experiments indicate a $p H$-independent process. Hence, a greater difference in potential can be expected for the two waves in acidic media. For FeTSPc adsorbed on $\mathrm{Cp}$, this means that experiments at lower $\mathrm{pH}$ values than those used in Zagal's experiments (even though the stability of the complexes therein is far less) are expected to give additional information.

For comparison, oxygen reduction was also studied at polypyrrole without a catalyst and with CoTSPc molecularly dispersed in it.

\section{EXPERIMENTAL}

CoTSPc and FeTSPc were synthesized according to the methods described by Weber and Busch [8]. All other chemicals were commercially available and used without further purification except the pyrrole, which was distilled before use.

A rotating ring-disc electrode (RRDE) was used, with a Cp disc $\left(0.52 \mathrm{~cm}^{2}\right)$ and a Pt ring. The electrode was polished with $0.3 \mu \mathrm{m}$ alumina before each experiment to obtain a flat surface, free of adsorbed species. The alumina was removed from the disc by cleaning it in an ultrasonic bath for $1 \mathrm{~min}$.

In some cases, the catalyst (FeTSPc) was applied to the disc by dipping the electrode into a solution of $10^{-3} M$ FeTSPc in $1 M \mathrm{KOH}$ for $1 \mathrm{~min}$ and thereafter flushing with distilled water. The reason for using $1 \mathrm{M} \mathrm{KOH}$ solutions has been outlined in a previous paper [3].

In other cases, the disc was modified with a polypyrrole/FeTSPc (or CoTSPc) layer by electrooxidation of pyrrole (solution containing $1 \%$ pyrrole and $10^{-3} \mathrm{M} \mathrm{Fe}$ (or $\mathrm{Co}$ ) $\mathrm{TSPc}^{4-}$ anions in water) in a galvanostatic way with a current of $0.2 \mathrm{~mA}$. Since the electrooxidation of pyrrole gives a polymer with positive charges, these are compensated by negatively charged $\mathrm{FeTSPc}^{4-}$ (or $\mathrm{CoTSPc}^{4-}$ ) anions $[4,5,9]$. By varying the time, layers of different thickness are produced. For some experiments FeTSPc was replaced by $\mathrm{LiClO}_{4}$, which results in a polypyrrole layer without catalytically active material.

The electrochemical experiments were carried out in a standard three-compartment electrochemical cell filled with $100 \mathrm{ml}$ of electrolyte. As electrolytes both acidic $\left(0.05 \mathrm{M} \mathrm{H}_{2} \mathrm{SO}_{4}\right)$ and alkaline $(0.1 \mathrm{M} \mathrm{KOH})$ solutions were used, or in some cases buffer solutions with the compositions shown in Table 1. To the buffer solutions, $1 \mathrm{M} \mathrm{KNO}$ was added to ensure good conductivity. For characterization of the electrode, cyclic voltammatry was carried out in oxygen-free solutions. The oxygen reduction was measured in oxygen-saturated solutions using the rotating-disc electrode technique. In a few experiments the ring was used to detect the hydrogen peroxide possibly produced at the disc. To achieve quantitative oxidation of the hydrogen peroxide, the ring was slightly platinized and maintained at a potential of $1.2 \mathrm{~V}$ (vs. RHE).

The electrochemical measurements were carried out using a Tacussel bipotentiostat (Bipad). The counter-electrode consisted of a $\mathrm{Pt}$ foil, and as the reference 


\section{TABLE 1}

Compositions of the buffer solutions used. Twice-distilled water was addded to the mixtures until a volume of $500 \mathrm{ml}$ was reached. The buffer solutions were made in $1 M$ in $\mathrm{KNO}_{3}$

\begin{tabular}{|c|c|}
\hline$\overline{\mathrm{pH}}$ & Composition of solution \\
\hline 0 & $1 \mathrm{M} \mathrm{HClO}_{4}$ \\
\hline 2 & $125 \mathrm{ml} 0.2 M \mathrm{KCl}+65 \mathrm{ml} 0.1 \mathrm{M} \mathrm{HCl}$ \\
\hline 4 & $250 \mathrm{ml} 0.1 \mathrm{M} \mathrm{KH}$-phthalate $+0.5 \mathrm{ml} 0.1 \mathrm{M} \mathrm{HCl}$ \\
\hline 6 & 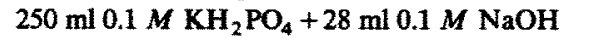 \\
\hline
\end{tabular}

electrode, a reversible Pt hydrogen electrode (RHE) was used. All potentials in this paper are given with respect to this RHE.

\section{RESULTS AND DISCUSSION}

Oxygen reduction at polypyrrole films applied on $C p$

Figure 1a shows a typical result of the measurement of the oxygen reduction in acidic solution $\left(0.05 \mathrm{M} \mathrm{H}_{2} \mathrm{SO}_{4}\right)$ for a polypyrrole layer with a thickness equivalent to $2.0 \mathrm{mC}$. In this figure the cyclic voltammogram (dotted line) for the layer in oxygen-free solution is also drawn, so the oxygen reduction current includes a relatively high capacitive background current. To determine the true oxygen reduction current, the curve measured in oxygen-free solution is subtracted from the curve recorded in oxygen-saturated solution.

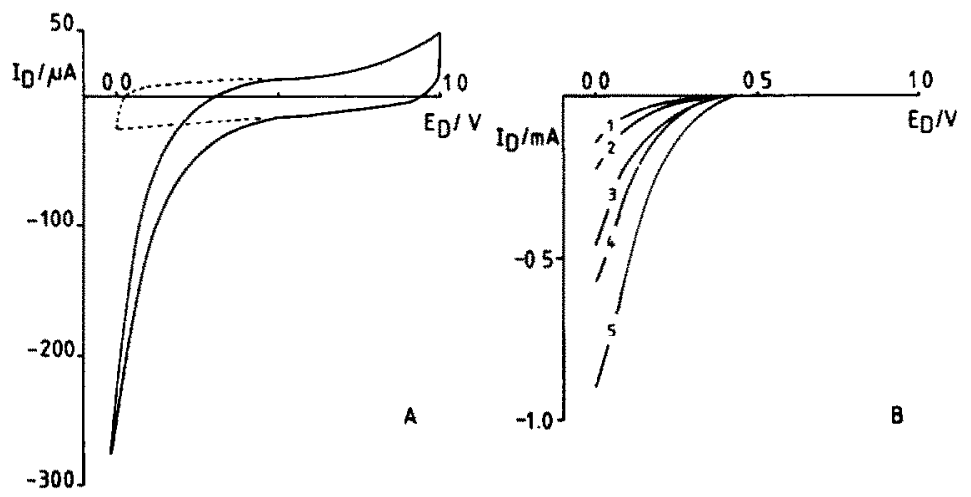

Fig. 1. (a) Oxygen reduction on a polypyrrole/FeTSPc layer. Thickness of the layer: $2.0 \mathrm{mC}$. Electrolyte: $0.05 \mathrm{M} \mathrm{H}_{2} \mathrm{SO}_{4}$, oxygen-saturated; scan rate $=50 \mathrm{mV} \mathrm{s}^{-1}$; rotation frequency $=64 \mathrm{~s}^{-1}$. (b) Oxygen reduction as a function of the thickness of the polypyrrole (PP) layer attached to a rotating-disc electrode. Electrolyte: $0.05 \mathrm{M} \mathrm{H}_{2} \mathrm{SO}_{4}$, oxygen-saturated; scan rate $=50 \mathrm{mV} \mathrm{s}^{-1}$; rotation frequency $=64$ $\mathrm{s}^{-1}$. Thickness of the PP layer/mC: (1) 0.50 ; (2) 2.0 ; (3) 6.0 ; (4) $12.1 ;$ (5) 30.0 . 


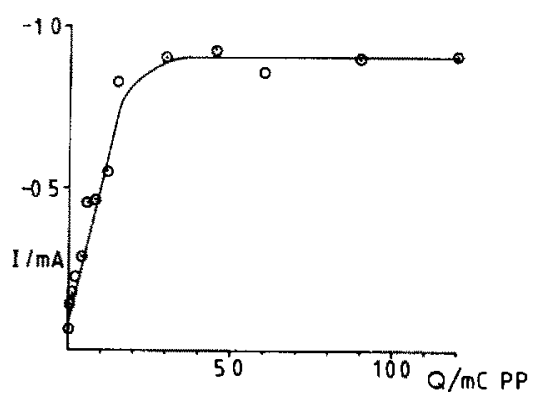

Fig. 2. Oxygen reduction current at a potential of $0 \mathrm{~V}$ plotted as a function of the thickness of the polypyrrole layer and corrected for the capacitive background current for the polypyrrole itself (see text). Electrolyte: $0.05 \mathrm{M} \mathrm{H}_{2} \mathrm{SO}_{4}$, oxygen-saturated; scan rate $=50 \mathrm{mV} \mathrm{s}^{-1}$; rotation frequency $=64 \mathrm{~s}^{-1}$.

Figure $1 \mathrm{~b}$ displays the oxygen reduction behaviour at polypyrrole, without any catalyst incorporated in it, as a function of the layer thickness. The layer thickness is expressed as the charge passed during the formation (electrooxidation of pyrrole) of polypyrrole. According to Diaz and Castillo [10], $24 \mathrm{mC} \mathrm{cm}^{-2}$ corresponds to a thickness of $0.1 \mu \mathrm{m}$, which means that in our case $1 \mathrm{mC}$ corresponds to a layer thickness of $8.3 \mathrm{~nm}$. Figure $1 \mathrm{~b}$ shows that polypyrrole is rather inactive for oxygen reduction, although with increasing layer thickness, the activity apparently rises due to the increase of the surface area of the film, as is shown by the higher capacitive currents obtained for the respective films in oxygen-free solutions.

When the layer thickness is still further increased, we could expect that for larger values an oxygen molecule cannot diffuse through the whole layer, on the time scale of the experiment. This leads to a situation where the reduction of oxygen takes place only in the outer parts, i.e. the electrolyte side of the film. The result will be a limitation of the reduction current if the conductivity of the layer does not become a limiting factor too. A general treatment of these phenomena is given in a paper by Andrieux et al. [11]. That this really happens is shown in Fig. 2, where the oxygen reduction currents, measured at a potential of $0 \mathrm{~V}$ (vs. RHE), are plotted as a function of the layer thickness. These results indicate that an oxygen molecule can diffuse through a polypyrrole layer up to a thickness cquivalent to $20 \mathrm{mC}(=0.17$ $\mu \mathrm{m})$.

\section{Oxygen reduction at FeTSPc incorporated in polypyrrole}

In Fig. 3 cyclic voltammograms are given for FeTSPc incorporated in polypyrrole (A) and for FeTSPc adsorbed on pyrolytic graphite (B). Both voltammograms were measured in $\mathrm{O}_{2}$-free $0.05 \mathrm{M} \mathrm{H}_{2} \mathrm{SO}_{4}$. Note the difference in current scales. The dotted lines indicated the background curves measured for a $30 \mathrm{mC}$ polypyrrole film by recording its cyclic voltammogram with $\mathrm{ClO}_{4}^{-}$as the counter-ion instead of FeTSPc. For the adsorbed FeTSPc layer, the cyclic voltammogram of $\mathrm{Cp}$ without any catalyst is used as the background current. Just as for FeTSPc adsorbed on Cp 


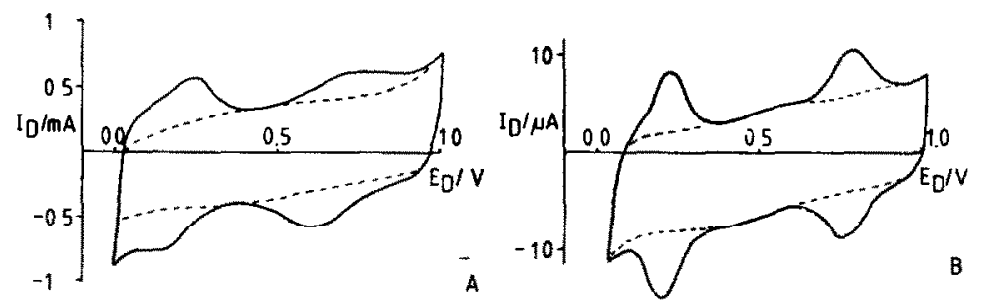

Fig. 3. Cyclic voltammograms recorded in oxygen-free $0.05 \mathrm{M} \mathrm{H}_{2} \mathrm{SO}_{4}$. Scan rate $=100 \mathrm{mV} \mathrm{s}^{-1}$. (A) 30 mC FeTSPc layer; (B) FeTSPc adsorbed on Cp.

[1,3], two redox processes are detected for FeTSPc incorporated in polypyrrole in the potential region of interest. In polypyrrole, the two redox processes are less reversible than those for the adsorbed FeTSPc. Perhaps the conductivity of the polypyrrole layer is not high enough to allow a completely reversible process. It is also possible that the electron transfer from the polymer to the metal complex is a kinetically slow process. A shift of about $100 \mathrm{mV}$ to lower potentials is also observed for the redox process at the highest potential, for the polymer with incorporated vs. adsorbed FeTSPc. It is rather obvious that this must be ascribed to an interaction between the nitrogen atom of the pyrrole unit and the metal ion.

The amount of FeTSPc present on the surface can be calculated from the surface area under the redox peaks. For FeTSPc incorporated in polypyrrole, a charge of approximately $600 \mu \mathrm{C}$ is determined for each of the four redox peaks. When a redox process with $n=1$ is assumed, this results in a coverage of $1.2 \times 10^{-8} \mathrm{~mol} \mathrm{~cm}^{-2}$. This value is in reasonable agreement with the value of $1.67 \times 10^{-8} \mathrm{~mol} \mathrm{~cm}^{-2}$ that can be calculated for the coverage of a $30 \mathrm{mC}$ polypyrrole-FeTSPc layer. The basis of this calculation is the assumption [6] that two electrons per molecule are involved in the oxidation of pyrrole to neutral polypyrrole, and that in the oxidized form of polypyrole every four pyrrole units carries one positive charge. As we have shown earlier [3], no adsorption of FeTSPc occurs on Cp under the conditions used for the electrooxidation of pyrrole. This means that for a $1 \mathrm{mC}$ thick layer, $4 \times 10^{-10} \mathrm{~mol}$ $\mathrm{cm}^{-2}$ is the total coverage. The redox peaks in the cyclic voltammogram of Fig. 3B correspond to a coverage of $1.1 \times 10^{-10} \mathrm{~mol} \mathrm{~cm}^{-2}$ for the adsorbed FeTSPc.

For different $\mathrm{pHs}$, the oxygen reduction results at FeTSPc adsorbed on $\mathrm{Cp}$ are given in Fig. 4. The figure clearly shows that, from $\mathrm{pH} 13$ to $\mathrm{pH} \mathrm{6,} \mathrm{the} \mathrm{main} \mathrm{wave} \mathrm{as}$ indicated by the half-wave potential shifts from about 600 to $200 \mathrm{mV}$, while the prewave shifts from about 800 to $650 \mathrm{mV}$. From $\mathrm{pH} 6$ to lower values, the two waves gradually merge, and it is not easy to determine whether the main wave or the prewave will become dominant, especially in the $\mathrm{pH}$ range from 2 to 0 . It follows from rotating ring-disc experiments, that in alkaline solutions both waves yield water while in acidic solutions, hydrogen peroxide is the end product.

The study of the influence of the layer thickness on oxygen reduction at FeTSPc incorporated in polypyrrole resulted in the $i-\mathrm{E}$ curves of Fig. 5 . The $i-E$ curve 

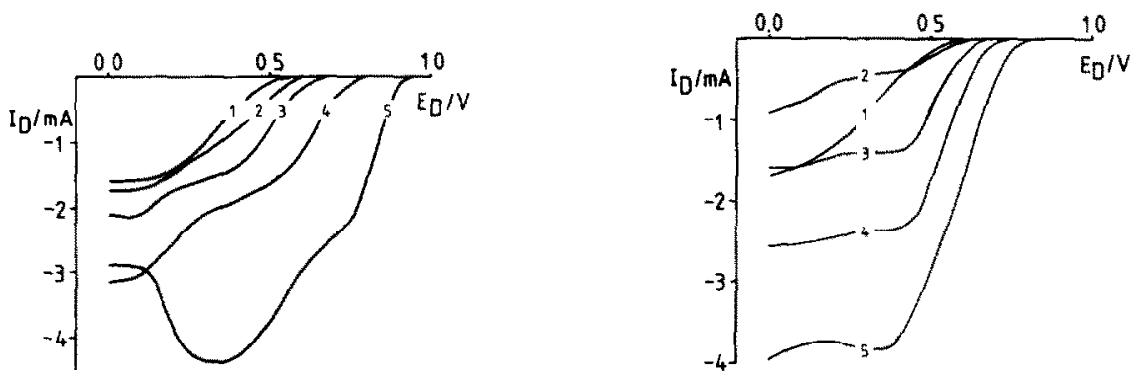

Fig. 4. Oxygen reduction at different pHs for FeTSPc adsorbed on Cp. Curves 1-5 are measured at a pH of $0,2,4,6$ and 13, respectively. For curves 1-4 the buffer solutions of Table 1 were used. Curve 5 was recorded in $0.1 \mathrm{M} \mathrm{KOH}$. Oxygen-saturated electrolyte; scan rate $=50 \mathrm{mV} \mathrm{s}^{-1}$; rotation frequency $=64$ $s^{-1}$.

Fig. 5. $i-E$ curves for the oxygen reduction at FeTSPc/polypyrrole layers of different thicknesses. Electrolyte: $0.05 \mathrm{M} \mathrm{H}_{2} \mathrm{SO}_{4}$, oxygen-saturated; scan rate $=200 \mathrm{mV} \mathrm{s}^{-1}$; rotation frequency $=64 \mathrm{~s}^{-1}$. (1) FeTSPc adsorbed on Cp; (2) $0.20 \mathrm{mC}$ FeTSPc/PP; (3) $0.58 \mathrm{mC} \mathrm{FeTSPc/PP;} \mathrm{(4)} 2.0 \mathrm{mC} \mathrm{FeTSPc} / \mathrm{PP}$; (5) $15.0 \mathrm{mC} \mathrm{FeTSPc} / \mathrm{PP}$.

obtained for FeTSPc adsorbed on $\mathrm{Cp}$ is also given in this figure to enable a comparison. A problem encountered here is the instability of the film. With repeated scanning, the activity decreases, being most pronounced for very thin films; e.g. for the $0.58 \mathrm{mC}$ film, the second scan gave a $40 \%$ smaller current at a scan rate of $200 \mathrm{mV} \mathrm{s}^{-1}$, whereas a $15 \mathrm{mC}$ film showed only a $10 \%$ decrease in current after a few scans. The better stability of the thicker layer is due to the higher coverage with catalyst molecules for these layers.

Therefore, a high scan rate $\left(200 \mathrm{mV} \mathrm{s}^{-1}\right)$ was chosen and only the first scan is given in Fig. 5. The behaviour of FeTSPc, with regard to the influence of the layer thickness, differs from that of CoTSPc (Fig. 6), which was previously investigated by us [6]. There, a theoretical description for the improvement of the activity based

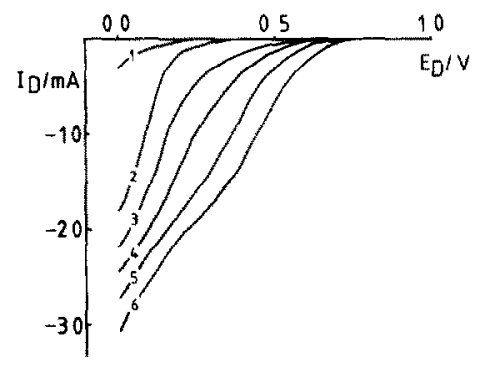

Fig. 6. Oxygen reduction behaviour at CoTSPc/polypyrrole layers of different thicknesses. The results for pyrolytic graphite (Cp) itself (curve 1) and CoTSPe adsorbed on $\mathrm{Cp}$ (curve 2) are also given. Electrolyte: $0.05 \mathrm{MH}_{2} \mathrm{SO}_{4}$, oxygen-saturated; scan rate $=50 \mathrm{mV} \mathrm{s}$; rotation frequency $=64 \mathrm{~s}^{-1}$. Thickness of the CoTSPc/PP layer/mC: (3) 2.1 ; (4) 6.2 ; (5) 12.1 ; (6) 30.0 . 
on the increased number of active sites is given. It was concluded on theoretical arguments that a ten-fold increase in the number of active catalyst molecules caused a shift of the half-wave potential with a value equal to the Tafel slope for the same reaction. For CoTSPc in polypyrrole, the Tafel slope of $-155 \mathrm{mV}$ in $0.05 \mathrm{M} \mathrm{H}_{2} \mathrm{SO}_{4}$ agrees well with the observed shift $(155 \mathrm{mV})$ in half-wave potential for a ten-fold increase of the number of active sites.

By comparing the curves for FeTSPc incorporated in polypyrrole (Fig. 5, curves 2-5) with each other, an increasing limiting current is observed as the layer thickness increases. Half-wave potentials can be determined if each curve is considered to be a complete wave. The resulting shift in half-wave potential on going from curve 2 to curve 5 is small and has a value of $42 \mathrm{mV}$ for a ten-fold increase in the number of active sites. This is less than the Tafel slope of FeTSPc incorporated in polypyrrole (about $-100 \mathrm{mV}$ ) which could be determined for curve 5 , for instance. This indicates a quasi-reversible reaction, because for a completely irreversible reaction (as for CoTSPc) the observed shift in the half-wave potential for a ten-fold increase of active sites should be equal to, and not less than, the Tafel slope.

When the same calculation model is applied to adsorbed FeTSPc in comparison with FeTSPc incorporated in polypyrrole, from the difference of about $170 \mathrm{mV}$ for the half-wave potentials of curve 1 (i.e. the adsorbed layer with $1.1 \times 10^{-10} \mathrm{~mol}$ $\mathrm{cm}^{-2}$ ) and curve 3 (with a coverage of $2.4 \times 10^{-10} \mathrm{~mol} \mathrm{~cm}^{-2}$ ), a shift of $780 \mathrm{mV}$ for a ten-fold increase in the number of active sites can be determined. This leads to a very unlikely high value for the Tafel slope. So, the mechanism of oxygen reduction at FeTSPc incorporated in polypyrrole must be different from that of the adsorbed layer. In this last case, in $0.05 \mathrm{M} \mathrm{H}_{2} \mathrm{SO}_{4}$ the prewave has almost completely disappeared (curve 1). For FeTSPc/polypyrrole layers, this prewave reappears and this causes the considerable increase in activity.

We have argued that the "kinetic limitation" as observed for the prewave in basic media is caused by the fact that there are only few dimers present on the surface [3]. The same arguments, applied here, lead to the conclusion that in $0.05 M \mathrm{H}_{2} \mathrm{SO}_{4}$, FeTSPc is almost not present in the dimer form on the graphite surface. For $\mathrm{FeTSPc}$ /polypyrrole films two explanations are now possible:

(1) The ratio of dimer to monomer species is the same as that for FeTSPc adsorbed on Cp. By increasing the amount of FeTSPc on the electrode via incorporation in polypyrrole, the number of dimer sites also increases and the prewave is reinforced.

(2) The dimerization is favoured in polypyrrole, so relatively more dimers are present in $\mathrm{FeTSPc}$ /polypyrrole films, which also results in a stronger prewave. A closer examination of Fig. 5 reveals that the results are in favour of the second explanation. For curve $2(0.2 \mathrm{mC})$, a slightly higher activity is observed at low overpotential than for FeTSPc adsorbed on graphite (curve 1), in spite of the lower coverage in the first case $\left(0.8 \times 10^{-10}\right.$ compared with $\left.1.1 \times 10^{-10} \mathrm{~mol} \mathrm{~cm}^{-2}\right)$. In the potential region where the second wave is dominant, the electrode prepared by adsorption acts as the more active electrode. This means that the prewave is relatively more important for FeTSPc incorporated in polypyrrole; hence, in poly- 


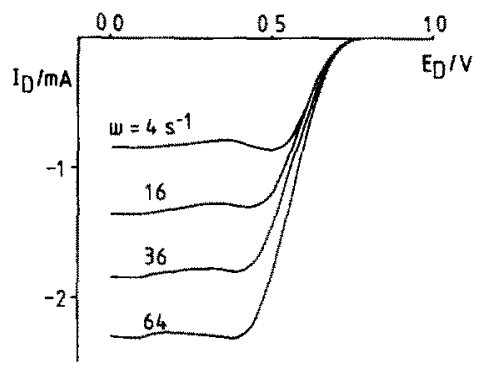

Fig. 7. Rotation frequency dependence of the oxygen reduction at a $1 \mathrm{mC} \mathrm{FeTSPc/polypyrrole} \mathrm{layer.}$ The different frequencies are given in the figure. Electrolyte: $0.05 \mathrm{M} \mathrm{H}_{2} \mathrm{SO}_{4}$, oxygen-saturated; scan rate $=200 \mathrm{mV} \mathrm{s}^{-1}$.

pyrrole relatively more dimer sites of FeTSPc are present than in an adsorption layer.

In Fig. 7 the oxygen reduction in $0.05 \mathrm{M} \mathrm{H}_{2} \mathrm{SO}_{4}$ is given as a function of the rotation frequency for a $1 \mathrm{mC} \mathrm{FeTSPc/polypyrrole} \mathrm{layer.} \mathrm{For} \mathrm{each} \mathrm{rotation}$ frequency a freshly prepared layer is used because of the already mentioned rapid deactivation. As in the preceding experiments, again a high scan rate of $200 \mathrm{mV} \mathrm{s}^{-1}$ is chosen to prevent deactivation during the scan. The instability of the FeTSPc/ polypyrrole film hampers the investigations severely, but it also gives a clue to the mechanism of oxygen reduction. Electrodes prepared by irreversible adsorption of FeTSPc on graphite and electrodes covered with CoTSPc/polypyrrole layers show a greater stability. Therefore, it is the combination of FeTSPc and polypyrrole which is the cause of the strong deactivation. If we realize that small configurational changes of the polymer are probably enough to destroy a dimer site, we can expect a rapid decrease in activity.

From Fig. 7, a half-wave potential of about $570 \mathrm{mV}$ can be determined for a 1 $\mathrm{mC} \mathrm{FeTSPc}$ / polypyrrole layer. For the substrate, $\mathrm{Cp}$ (without catalysis), it is not possible to determine a half-wave potential under these conditions, but it can be argued that the half-wave potential must be below $0 \mathrm{~V}$. In our view, a catalyst which causes such a large increase in activity deserves some attention, and this justifies these experiments, notwithstanding the high instability of the layer.

The curves depicted in Fig. 7 display almost no "kinetic limitation", which means that a $1 \mathrm{mC}$ thick layer contains enough dimer sites to obtain a Levich diffusion behaviour [3]. In Fig. 8, the rotation frequency dependence for FeTSPc irreversibly adsorbed on $\mathrm{Cp}$ is given. This shows again, if compared with Fig. 7. the almost complete lack of the prewave in the case of electrodes prepared by irreversible adsorption.

For a thin FeTSPc/polypyrrole layer $(0.58 \mathrm{mC})$, the ring current has also been measured as a function of the disc potential. These results are given in Fig. 9. With a value of 0.145 for the collection efficiency, it follows that $84 \%$ of the oxygen is reduced to hydrogen peroxide. As the layer thickness increases, that part of the 


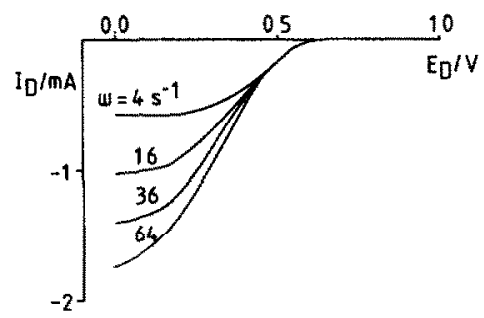

Fig. 8. Rotation frequency dependence of the oxygen reduction at FeTSPc adsorbed on Cp. The different frequencies are given in the figure. Electrolyte: $0.05 \mathrm{M} \mathrm{H}_{2} \mathrm{SO}_{4}$, oxygen-saturated; scan rate $=200 \mathrm{mV}$ $\mathrm{s}^{-1}$.

oxygen which is reduced to water also increases. Figure 5 shows a disc current of about $4 \mathrm{~mA}$ for a $15 \mathrm{mC} \mathrm{FeTSPc}$ / polypyrrole layer (curve 5). If it is assumed that the same ratio of water to hydrogen peroxide production occurs as for the $0.58 \mathrm{mC}$ layer, then a limiting current of $6.9 \mathrm{~mA}$ can be determined for the quantitative reduction of oxygen to water. This value far exceeds the theoretical value of $5.2 \mathrm{~mA}$, as can be calculated from the diffusion coefficient [12] and the solubility [13] of oxygen in $0.05 \mathrm{M} \mathrm{H}_{2} \mathrm{SO}_{4}$. The difference between the values can be explained only by an increase in that part of the oxygen which is reduced to water.

In order to present a complete treatment of the oxygen reduction on FeTSPc incorporated in polypyrrole, some results obtained in $0.1 M \mathrm{KOH}$ are given in Fig. 10, together with the results for FeTSPc irreversibly adsorbed on $\mathrm{Cp}$. For the FeTSPc/polypyrrole layer, only one wave is observed. The higher activity of the adsorbed FeTSPc at low overpotential, compared with the vast amount of FeTSPc incorporated in polypyrrole, is probably due to the limited conductivity of the polypyrrole layer. Perhaps, also the instability in alkaline media of polypyrrole itself, as reported by some authors [14], plays a role. Since the prewave and the main wave almost coincide in alkaline media, it is not expected that a more detailed study

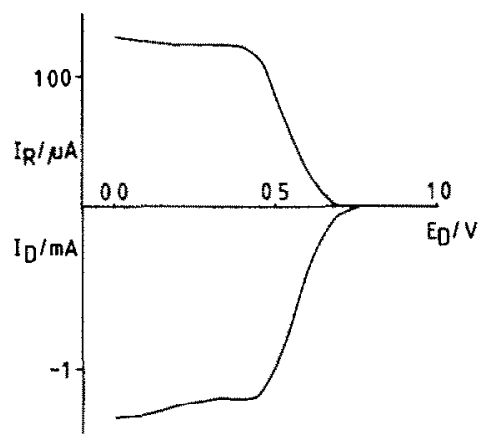

Fig. 9. Disc and ring currents as a function of the disc potential for a $0.58 \mathrm{mC} \mathrm{FeTSPc}$ /polypyrrole layer. Electrolyte: $0.05 \mathrm{M} \mathrm{H}_{2} \mathrm{SO}_{4}$, oxygen-saturated; scan rate $=200 \mathrm{mV} \mathrm{s}^{-1}$; rotation frequency $=64 \mathrm{~s}^{-1}$. 


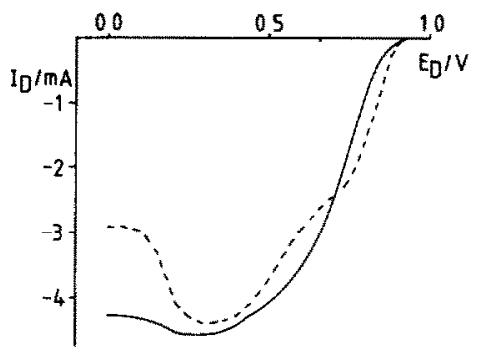

Fig. 10. Comparison between the oxygen reduction at FeTSPc adsorbed on $\mathrm{Cp}$ and on FeTSPc incorporated in polypyrrole in $0.1 \mathrm{M} \mathrm{KOH}$. (-) $15 \mathrm{mC} \mathrm{FeTSPc} /$ polypyrrole; $(\cdots \cdots) 30 \mathrm{mC}$ polypyrrole; $(--\infty)$ FeTSPc adsorbed on Cp. Oxygen-saturated electrolyte; scan rate $=50 \mathrm{mV} \mathrm{s}^{-1}$; rotation frequency $=64 \mathrm{~s}^{-1}$.

of the oxygen reduction on FeTSPc/polypyrrole films in these media will give more insight into the mechanism of oxygen reduction on FeTSPc.

\section{CONCLUDING REMARKS}

We have given some evidence for an oxygen reduction mechanism operating by dimers at FeTSPc incorporated in polypyrrole. To prove this mechanism completely, more experiments are necessary. Investigations are currently in progress to detect the postulated dimer species. With respect to the proposed mechanism, the oxygen reduction behaviour of a di-iron phthalocyanine, analogous to the cofacial dicobaltporphyrin complexes of Collman et al. [15], if possible to synthesize, would be interesting. The cofacial dicobaltporphyrin complex gives reduction of oxygen to water at a relatively low overpotential in acidic media. Perhaps, the same results can be obtained for a comparable di-iron phthalocyanine complex.

\section{ACKNOWLEDGEMENTS}

The present investigations were carried out with the support of the Netherlands Foundation for Chemical Research (S.O.N.) and with financial aid from the Netherlands Organization for the Advancement of Pure Research (Z.W.O.).

\section{REFERENCES}

1 J. Zagal, P. Bindra and E. Yeager, J. Electrochem. Soc., 127 (1980) 1506.

2 A. van der Putten, A. Elzing, W. Visscher and E. Barendrecht, J. Electroanal. Chem., 214 (1986) 523.

3 A. Elzing, A. van der Putten, W. Visscher and R. Barendrecht, J. Electroanal. Chem., 233 (1987) 99.

4 R.A. Bull, F.R. Fan and A.J. Bard, J. Electrochem. Soc., 131 (1984) 687.

5 M.I. Florit, W.E. O'Grady, C.A. Linkous, T. Skotheim and M. Rosenthal, Extended Abstracts, Vol. 84-1, The Electrochem. Soc., Prínceton, 1984, Abstract No. 415.

6 A. Elzing, A. van der Putten, W. Visscher and E. Barendrecht, J. Electroanal. Chem., 200 (1986) 313.

7 J.H. Zagal-Moya, 'Thesis, Case Western Reserve University, Cleveland, 1978. 
8 J.H. Weber and D.H. Busch, J. Inorg. Chem., 4 (1965) 469.

9 A.F. Diaz, J.I. Castillo, J.A. Logan and W.Y. Lee, J. Electroanal. Chem., 129 (1981) 115.

10 A.F. Diaz and J.I. Castillo, J. Chem. Soc., Chem. Commun., (1980) 397.

11 C.P. Andrieux, J.M. Dumas-Bouchiat and J.M. Savéant, J. Electroanal. Chem., 131 (1982) 1.

12 K.K. Gubbins and R.D. Walker, Jr., J. Electrochem. Soc., 112 (1965) 469.

13 R.J. Millington, Science, 122 (1955) 1090.

14 E.M. Genies and A.A. Syed, Synth. Met., 10 (1984) 21.

15 J.P. Collman, P. Denisevich, Y. Konai, M. Marrocco, G. Koval and F.C. Anson, J. Am. Chem. Soc., $102(1980) 6027$. 